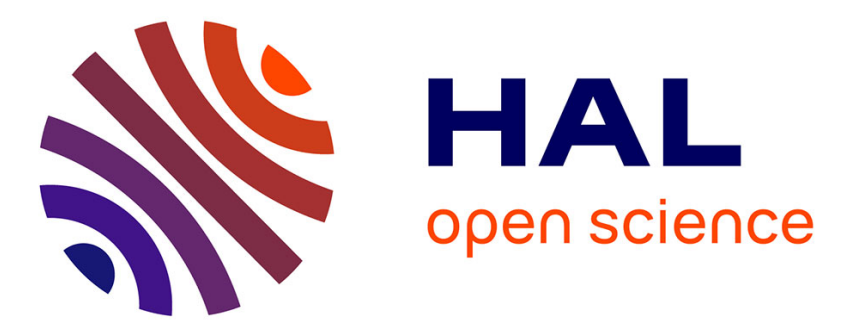

\title{
Post-discharge treatment of air effluents polluted by butyl-mercaptan: the role of nitrate radical
}

\author{
Yn Liu, L Braci, S Cavadias, S Ognier
}

\section{To cite this version:}

Yn Liu, L Braci, S Cavadias, S Ognier. Post-discharge treatment of air effluents polluted by butylmercaptan: the role of nitrate radical. Journal of Physics D: Applied Physics, 2011, 44 (9), pp.95202. 10.1088/0022-3727/44/9/095202 . hal-00599243

\section{HAL Id: hal-00599243 \\ https://hal.science/hal-00599243}

Submitted on 9 Jun 2011

HAL is a multi-disciplinary open access archive for the deposit and dissemination of scientific research documents, whether they are published or not. The documents may come from teaching and research institutions in France or abroad, or from public or private research centers.
L'archive ouverte pluridisciplinaire HAL, est destinée au dépôt et à la diffusion de documents scientifiques de niveau recherche, publiés ou non, émanant des établissements d'enseignement et de recherche français ou étrangers, des laboratoires publics ou privés. 


\title{
Post-discharge treatment of air effluents polluted by butyl- mercaptan: role of nitrate radical
}

\author{
YN Liu ${ }^{2}, \mathrm{~L} \mathrm{Braci}^{1}$, S Cavadias ${ }^{1}$ and S Ognier ${ }^{1}$ \\ ${ }^{1}$ UPMC Univ Paris 06, EA 3492, Laboratoire de Génie des Procédés et Traitements de \\ Surface, F-75005, Paris, France \\ ${ }^{2}$ School of Environmental Science and Engineering, Dong Hua University, C-201620, \\ Shanghai, China \\ E-mail: Stephanie-ognier@chimie-paristech.fr
}

\begin{abstract}
Dry air polluted by butyl-mercaptan was treated in a Dielectric Barrier Discharge (DBD) reactor at atmospheric pressure using air as plasmagene gas in discharge and postdischarge modes. The energy density was varied between 200 to $1300 \mathrm{~J} / \mathrm{L}$. To assess the treatment efficiency, the concentrations of buty-mercaptan, total Volatile Organic Compounds (VOCs) and $\mathrm{SO}_{2}$ were determined in the exhaust gas. Whatever the energy density was, the treatment efficiency was better in post-discharge mode. The butyl-mercaptan could be completely eliminated from $400 \mathrm{~J} / \mathrm{L}$ and $\mathrm{SO}_{2}$ selectivity was always low, below $10 \%$. Measurements of $\mathrm{CO}, \mathrm{CO}_{2}$ and total VOCs indicated that 50 to $70 \%$ of the reaction products were condensed on the reactor wall in the form of micro-droplets, depending on the energy density. FTIR and XPS techniques were used to characterize the reaction products which were soluble in water. These analyses indicated that the reaction products contain oxygen, nitrogen and sulphur in an oxidized form. A reaction mechanism involving hydrogen abstraction from the - $\mathrm{SH}$ bond by the nitrate radical was proposed, pointing out the important role of nitrate radicals $\mathrm{NO}_{3}$ in the reactivity of air flowing post-discharge.
\end{abstract}

\section{Introduction}

The mercaptans are sulfur-containing organic compounds with the general formula R-SH. They belong to the class of chemical pollutants called "Volatile Organic Compounds" (VOCs) if their vapour pressure is higher than $0.1 \mathrm{mmHg}$. These compounds are toxic and malodorous, they also represent danger for human health and ecosystem. It is thus of great importance to fight against this environmental pollution. Applications where mercaptans need to be removed from a gas effluent are for example the treatment of fumes produced during the fabrication of asphalt concrete or the treatment of natural gas.

The conventional oxidation techniques such as thermal or catalytic oxidation are not satisfactory because they require a lot of energy considering the very high conditions of temperature [1]. In the case of catalytic oxidation, the poisoning of catalyst by mercaptans is an additional problem [2]. It is therefore necessary to develop more effective technologies for the elimination of mercaptans in gaseous effluents.

Technologies based on the use of non-thermal plasma generated at atmospheric pressure are considered as relevant alternatives for the treatment of VOCs [3]. The advantage of plasma consists in its ability to generate high-energy electrons while keeping the background gas close to room temperature. Thus, a highly reactive environment is created without spending energy on gas heating as 
in thermal processes. Moreover, plasma techniques are flexible and easy to be implemented. Nowadays, most studies focus on processes combining plasma and heterogeneous catalysis with the objective to oxidise completely the pollutants into $\mathrm{CO}_{2}$ with an acceptable energetic cost $[4,5]$. However, such processes may not be adapted with mercaptans because of catalyst poisoning, which is the most crucial problem.

Consequently, our research team has developed an original process which has already been tested successfully with beta-pinene as a model pollutant [6]. In this process, the active species of the plasma are used to modify chemically the pollutants by partial oxidation reactions. As a result, the molecules become more polar and less volatile and in a second step, they can be trapped easily using techniques such as condensation, absorption or adsorption. With this strategy, the energy required is far lower that the energy needed for complete oxidation.

In this article the results obtained when air polluted by mercaptans is treated in discharge and post-discharge modes with the active species produced by non-thermal plasma generated at room temperature and atmospheric pressure with a Dielectric Barrier Discharge (DBD) are presented. The model sulfur molecule is butyl-mercaptan $\left(\mathrm{C}_{4} \mathrm{H}_{9}-\mathrm{SH}\right)$. To determine the treatment efficiency, the butyl-mercaptan concentration and the total VOC concentration in the exhaust gas phase have been measured. Advanced analysis techniques such as gas chromatography coupled to mass spectrometry (GC/MS) and X-ray Photoelectron Spectroscopy (XPS) have been also carried out to characterize the oxidation products. Special attention was dedicated to the comparison of discharge and post-discharge modes in order to (i) validate the best configuration and (ii) bring useful information on the species involved in the reactions.

\section{Material and methods}

\subsection{Experimental set-up}

Plasma treatment is operated in the DBD reactor as presented in figure 1 . The reactor is constituted by a $190 \mathrm{~mm}$ long and $2 \mathrm{~mm}$ thick glass tube with an internal diameter of $29 \mathrm{~mm}$. The stainless steel high voltage electrode is a $4 \mathrm{~mm}$ thick and $25 \mathrm{~mm}$ diameter disc. The space between high voltage electrode and the glass tube used as dielectric material is $2 \mathrm{~mm}$. A wire sheet (20 mm width and $2 \mathrm{~mm}$ thick) wrapped around the tube constitutes the ground electrode. A high voltage generator supplies from 5 to $30 \mathrm{kV}$ peak to peak $\left(\mathrm{U}_{\mathrm{pkpk}}\right)$ alternative voltage $(40 \mathrm{kHz})$. The voltage and the current are measured by a LeCroy LT 342, $500 \mathrm{MHz}$ digital oscilloscope. In the conditions of the experiments, the discharge is filamentary. The discharge power $\mathrm{P}$ was calculated by the integration on two entire periods of instant applied voltage and instant discharge current. The voltage signal applied to the high voltage electrode is measured with a high voltage probe (Tektronix model $75 \mathrm{MHz}$ bandwidth) connected to the oscilloscope. The discharge current is measured using the measurement set-up described in the figure 2. The energy density $D E(J / L)$ was defined as the ratio $P / Q$ where $Q$ is the gas flow $(\mathrm{L} / \mathrm{s})$ through the discharge. During the experiments, the discharge power was varied from 2 to 24 watts (DE from 100 to $1200 \mathrm{~J} / \mathrm{L}$ ).

$1.2 \mathrm{~L} / \mathrm{min}$ of pure air is injected at the gas inlet A to flow between the two electrodes. The synthetic polluted gaseous effluent is produced by bubbling $40 \mathrm{ml} / \mathrm{min}$ of air in liquid butyl-mercaptan thermostated at $20 \pm 1{ }^{\circ} \mathrm{C}$. As the bubbling flow is very low, the concentration was calculated supposing that the partial pressure of the pollutant equals its saturated vapour pressure (system in thermodynamic equilibrium). As a result, the concentration of butyl-mercaptan in the gaseous effluent is $47000 \pm 2500 \mathrm{ppm}$. This polluted air flow is either premixed with pure air and injected at the gas inlet A ("discharge" mode) or injected after the discharge zone at the gas inlet B ("post-discharge" mode). The distance of the gas inlet B from the electrode is $10 \mathrm{~mm}$. The air flow carrying the pollutant is low compared to the pure air flow so that the gas flow through the discharge could be considered identical whatever the location of pollutant injection is. 


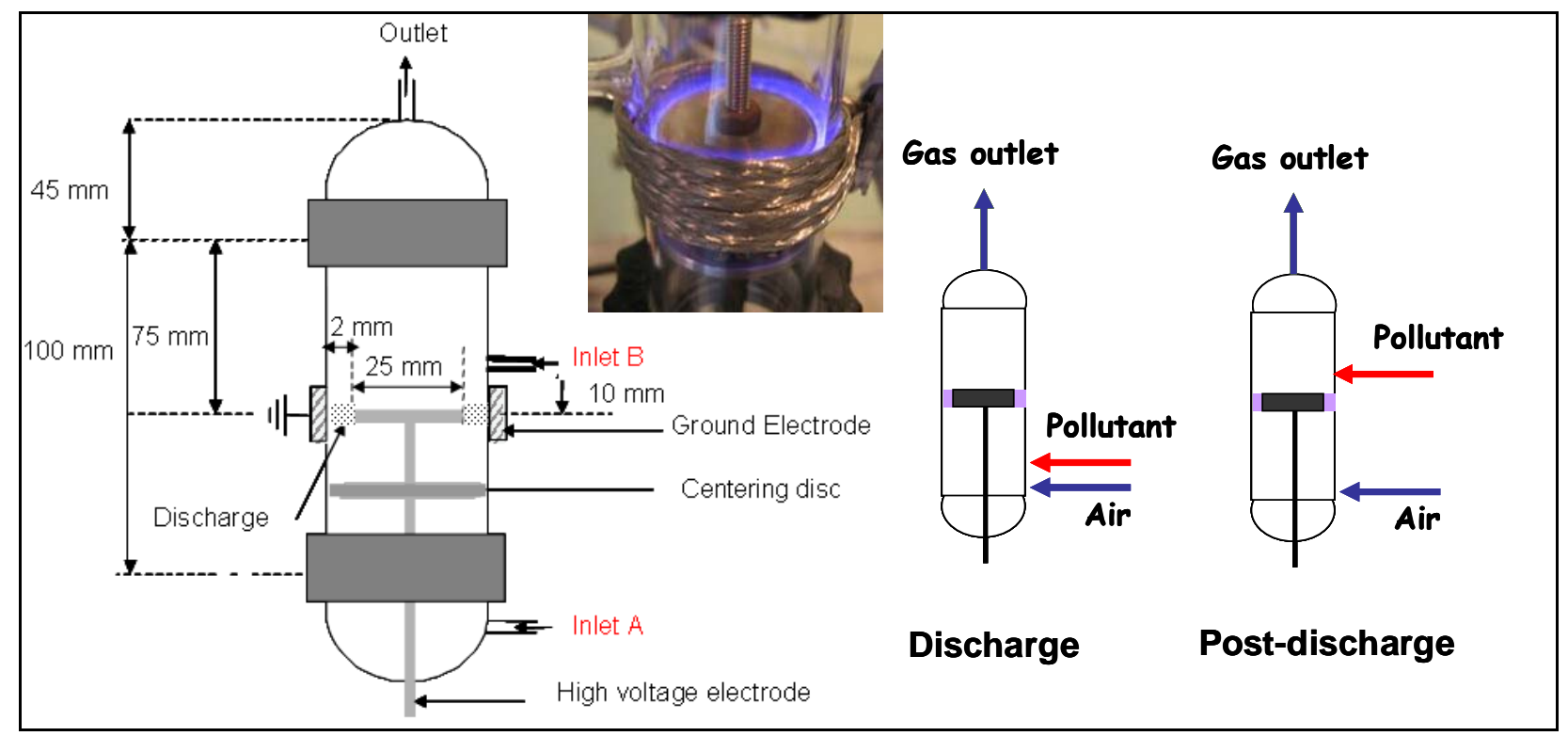

Figure 1. DBD reactor and configurations tested

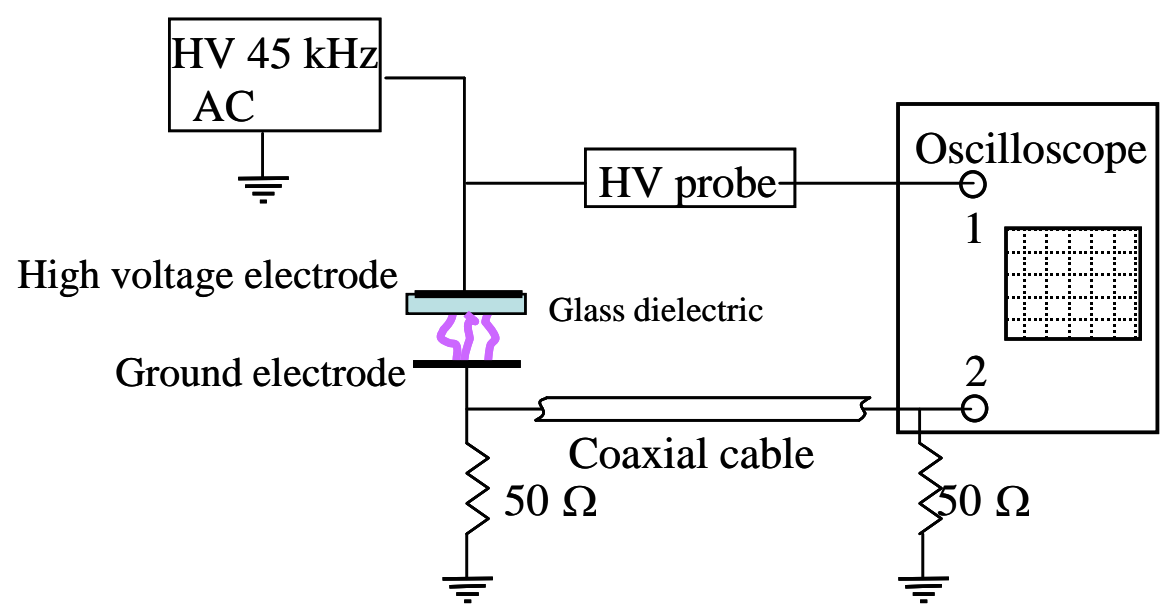

Figure 2. Set-up for power measurement 
Two types of analyses were carried out during the study: the analyses of the exhaust gas phase and the analyses of the products condensed on the reactor wall.

\subsubsection{Analyses of exhaust gas}

Gaseous samples were taken at the exit of the plasma reactor and injected in a gas chromatograph (Varian STAR, 3400Cx) equipped by a Flame Ionization Detector (FID). The injector and detector temperatures were set at $250{ }^{\circ} \mathrm{C}$ and high-purity He gas was used as the carrier gas. To determine the pollutant concentration, a capillary non polar column (BPX5, SGE) was used. The resolution of the GC was $100 \mathrm{ppm}$ for the measurement of butyl-mercaptan. To measure the concentration in total Volatile Organic Compounds (total VOCs), a short silica capillary (length $=10$ $\mathrm{cm}$ ) heated at $150^{\circ} \mathrm{C}$ and connected directly from the injector to the detector was used. In this case, the organic compounds are burned together in the flame (no separation) and one peak corresponding to the sum of the atoms of organic carbon present in the sample is obtained.

The concentration of Sulphur Dioxyde $\left(\mathrm{SO}_{2}\right)$ was determined according to the protocol of standard NF X43-013. In this method, the $\mathrm{SO}_{2}$ contained in the exhaust gas is absorbed in a solution containing $\mathrm{H}_{2} \mathrm{O}_{2}$ and dioxane to be converted into sulphate ions $\mathrm{SO}_{4}{ }^{2-}$. The sulphate ions are then measured by a spectrophotometric method using thorin.

$\mathrm{CO}$ and $\mathrm{CO}_{2}$ measurements were done using colorimetric indicator tubes (Gastec) with the ranges 100-2000 ppm for $\mathrm{CO}_{2}$ and 25-500 ppm for CO.

NOx measurements were carried out using colorimetric indicator tubes (Gastec) with the range 5-625 ppm.

\subsubsection{Characterization of oxidation products condensed on the reactor wall}

During the experiment, the formation on the reactor wall of a white deposit consisting of micro droplets was observed. For FTIR analysis, the deposit was recovered in $\mathrm{CH}_{2} \mathrm{Cl}_{2}$ and directly analysed. X-ray Photoelectron Spectroscopy (XPS) measurements were carried out to characterize the chemical composition of the oxidation products and the electronic character of sulphur element. In this method, a thin film of pure Polyethylene (PE) is pasted on the upper part of the reactor interior wall. The plasma treatment is then operated during 15 minutes, allowing the surface of the PE film to be covered by the treatment products. Finally, the PE film is removed and XPS analysis of its surface is carried out (XPS PHI 5600-ci, Physical Electronics, Eden Prairie, MN, USA) with Al Ka (1486.6 eV) source for spectrums on survey scan (chemical compositions) and $\mathrm{Mg} \mathrm{Ka}(1253,6 \mathrm{eV})$ source for high resolution spectrums. The spectrometer was run between 0 and $1400 \mathrm{eV}$ during $8 \mathrm{~min}$ for survey spectrums. High resolution spectrums on carbon (C) and sulfur (S) were also conducted using 10 and 20 scans respectively. A correction for binding energy was made to account for sample charging based on the C1s peak at $285.0 \mathrm{eV}$. The S2p peak curve was resolved using mixed LorentzianGaussian line shape.

\section{Experimental results}

\subsection{Air treatment efficiency}

\subsubsection{Butyl-mercaptan and VOCs removal efficiencies}

The concentrations of butyl-mercaptan in the exhaust gas were measured for treatments carried out in discharge and post-discharge modes at different energy densities. The air flow carrying the pollutant is low compared to the pure air flow, so that the energy density could be considered identical for both treatment modes, i.e., in discharge and post-discharge. The figure 2 shows the butyl-mercaptan removal as function of the applied energy density for the two configurations. 


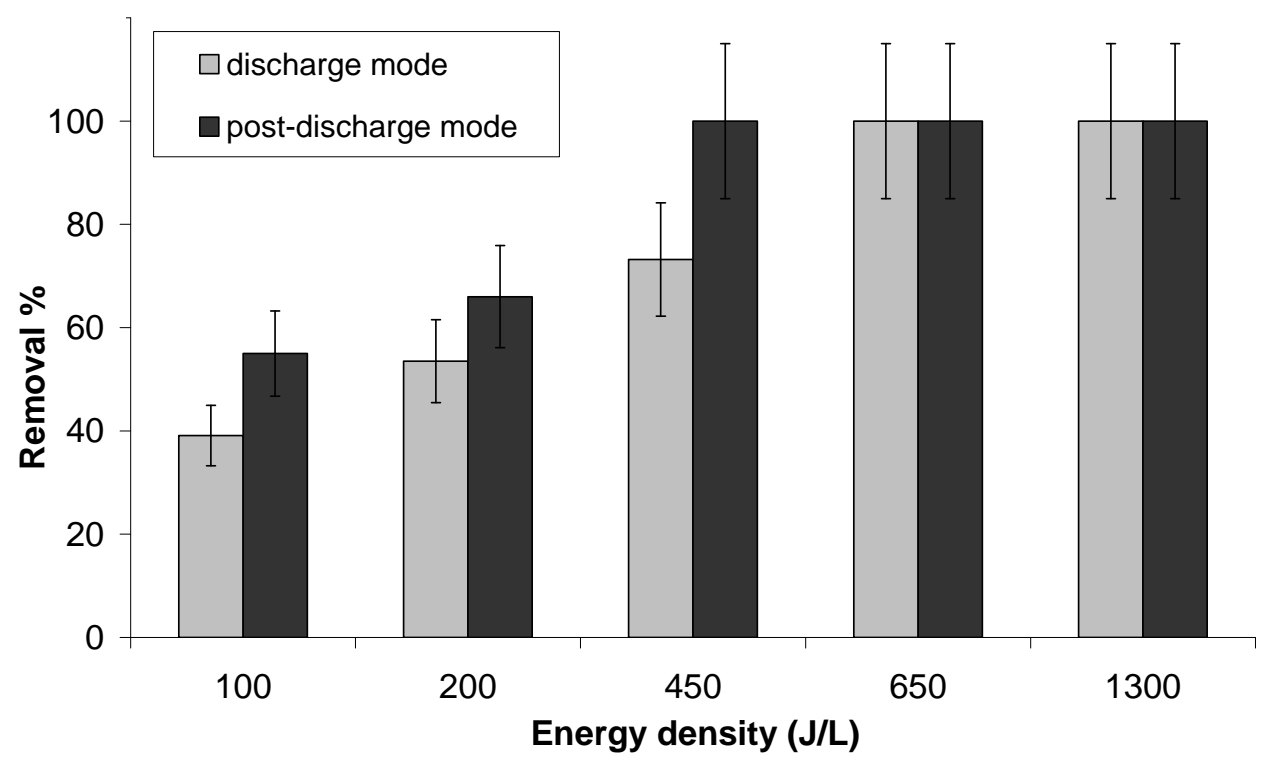

Figure 2. Butyl-mercaptan removal vs energy density in discharge and post-discharge

The butyl-mercaptan removal increases logically when the energy injected per liter of gas increases, indicating that the number of active species which can react with butyl-mercaptan increases when the energy density increases. Surprisingly, for a given energy density, the removal is slightly higher in the post-discharge mode compared to the discharge mode. For example, at $450 \mathrm{~J} / \mathrm{L}$, the removal is $100 \%$ in post-discharge mode but only $73 \%$ in discharge mode. In post-discharge mode, only the long-life active species produced by the discharge can react with the target pollutant whereas in discharge mode, the short-life species such as atomic oxygen can also participate to the oxidation reactions. The respective roles of short-life and long-life active species will be discussed in section 4 .

In our experimental conditions, the concentrations of $\mathrm{CO}$ and $\mathrm{CO}_{2}$ were always below the limits of detection (100 ppm for $\mathrm{CO}_{2}$ and $25 \mathrm{ppm}$ for $\mathrm{CO}$ ). Therefore, the oxidation of the pollutant was far from being complete. For example, in the case of a treatment in discharge mode with an energy density of $100 \mathrm{~J} / \mathrm{L}$, the removal of butyl-mercaptan is $40 \%$ and as a result, around $2900 \mathrm{ppm}$ of COx $\left(\mathrm{CO}+\mathrm{CO}_{2}\right)$ should be measured at the reactor outlet if the reaction was complete. According to these measurements, the COx selectivity never exceeded $4 \%$ whatever the energy density and the injection mode.

The total VOCs concentrations in the gas exiting the reactor were also determined for different energy densities. Useful information concerning the fate of the reaction products can be obtained when measuring total VOCs concentration. If the oxidation products are volatile enough to remain in the gaseous state, the total VOCs concentration should remain unchanged. On the contrary, if the volatility of the oxidation products is low enough so that they can condense on the reactor wall, the total VOCs concentration should decrease. The figure 3 presents the removal of total VOCs defined as $\frac{[\text { total VOCs }]^{\text {disch arge off }}-[\text { total VOCs }]^{\text {disch arge on }}}{[\text { total VOCs }]^{\text {disch arge off }}} \times 100$ as function of the energy density. 


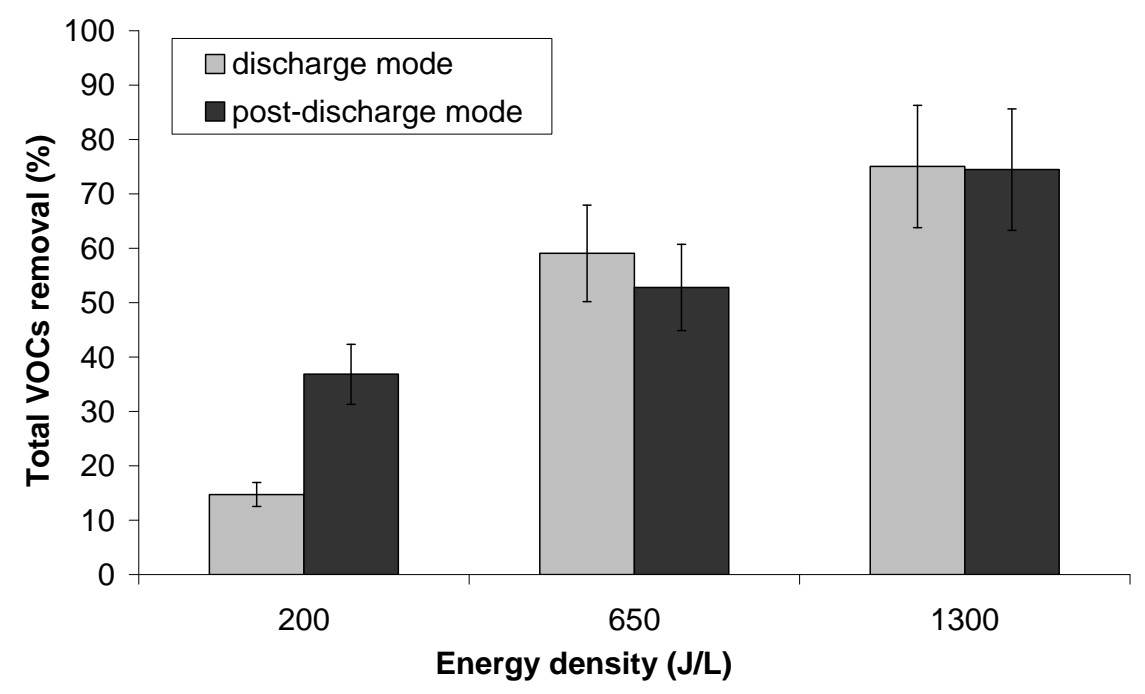

Figure 3. Relative concentrations of total VOCs as function of energy density

The removals of total VOCs are not equal to zero, which indicates that some of the carbonaceous products formed by the reaction of the butyl-mercaptan with the active species are no longer gaseous. These compounds are probably responsible for the formation of droplets on the reactor walls. In fact, the formation of a white deposit consisting of micro droplets in the upper part of the reactor wall was observed during the experiments. The reaction between butyl-mercaptan and plasma species is then responsible of the formation of products which are spontaneously trapped on the wall of the reactor. With these measurements, the efficiency of trapping was calculated. The trapping efficiency is the amount of organic carbon contained in the reaction products condensed on the reactor walls divided by the total amount of organic carbon contained in all the reaction products. It can be calculated by the following expression:

$$
\text { Trapping efficiency }=\frac{[\text { total VOCs }]^{\text {disch arge off }}-[\text { total VOCs }]^{\text {discharge on }}}{[\text { total VOCs }]^{\text {disch arge off }} \times\left(1-\tau_{\text {bu tan ethiol }}\right)} \times 100
$$

Where $\tau_{\text {bu tan ethiol }}$ is the butyl-mercaptan removal. The variation of the trapping efficiency as function of the energy density is represented in table 1.

Table 1. Trapping efficiency (\%)

\begin{tabular}{lccc}
\hline & $\mathbf{2 0 0} \mathbf{~ J / L}$ & $\mathbf{6 5 0} \mathbf{J} / \mathbf{L}$ & $\mathbf{1 3 0 0 ~ J / L}$ \\
\hline Discharge mode & 27 & 59 & 75 \\
Post-discharge mode & 56 & 53 & 74 \\
\hline
\end{tabular}

In post-discharge mode, the trapping efficiency is about $50 \%$ for low $(200 \mathrm{~J} / \mathrm{L})$ and medium $(650 \mathrm{~J} / \mathrm{L})$ energy densities. For $1300 \mathrm{~J} / \mathrm{L}$, a higher value of $74 \%$ is obtained. At high energy density, the higher amount of active species compared to the amount of pollutant may allow the formation of more condensable products.

\subsection{2. $\mathrm{SO}_{2}$ formation}


The sulfur dioxide $\mathrm{SO}_{2}$ was measured in the exhaust gas and the $\mathrm{SO}_{2}$ selectivity was calculated. It is defined as the ratio between the number of moles of $\mathrm{SO}_{2}$ that have been formed $n_{\mathrm{SO}_{2}}$ and the number of moles of butyl-mercaptan that have reacted $\mathrm{n}_{\text {butyl-mercaptan }}$ :

$$
\mathrm{SO}_{2} \text { selectivity }(\%)=100 \times \frac{\mathrm{n}_{\mathrm{SO}_{2}}}{\mathrm{n}_{\text {butyl-mercaptan }}}=100 \times \frac{\left[\mathrm{SO}_{2}\right]^{\text {out }}}{[\text { Butyl }- \text { mercaptan }]^{\text {in }}-[\text { butyl }- \text { mercaptan }]^{\text {out }}}
$$

Where $\left[\mathrm{SO}_{2}\right]^{\text {out }}$ is the molar concentration of $\mathrm{SO}_{2}$ at the reactor outlet, and [butyl-mercaptan] ${ }^{\text {in }}$ and [butyl-mercaptan] $^{\text {out }}$ the molar concentrations of butyl-mercaptan at the inlet and at the outlet of the reactor. Table 2 shows the $\mathrm{SO}_{2}$ selectivity for each energy density applied.

Table 2. $\mathrm{SO}_{2}$ selectivity as function of energy density (\%)

\begin{tabular}{lccc}
\hline & $\mathbf{2 0 0} \mathbf{J} / \mathbf{L}$ & $\mathbf{6 5 0} \mathbf{J} / \mathbf{L}$ & $\mathbf{1 3 0 0} \mathbf{~ J / L}$ \\
\hline Discharge mode & 9 & 11 & 37 \\
Post-discharge mode & 4 & 4 & 10 \\
\hline
\end{tabular}

Whatever the energy density, the $\mathrm{SO}_{2}$ selectivity is low $(<10 \%)$ what shows that the butyl-mercaptan is only partially oxidised. In post-discharge mode, the $\mathrm{SO}_{2}$ selectivity remains almost constant between 200 and $650 \mathrm{~J} / \mathrm{L}$ with a value of about $4 \%$ then increases abruptly to reach $10 \%$ at $1300 \mathrm{~J} / \mathrm{L}$.

\subsection{Characterization of the oxidation products condensed on the reactor wall}

Two different techniques were used to characterize the oxidation products trapped on the reactor wall. Whatever the technique used, there was no significant differences between the two configurations. Consequently, only the results obtained in post-discharge mode are presented.

\subsubsection{FTIR analysis}

FTIR analyses were carried out to obtain structural information about the oxidation products trapped on the reactor wall. On the spectrum presented in figure 4, the presence of $\mathrm{C}-\mathrm{H}$ bonds is shown by the three bands at 2874, 2930 and $2960 \mathrm{~cm}^{-1}$ and the band at $1466 \mathrm{~cm}^{-1}$. The broad absorption band around $3300 \mathrm{~cm}-1$ may correspond to the $\mathrm{OH}$ function of a carboxylic acid. At $1735 \mathrm{~cm}-1$, the characteristic band of $\mathrm{C}=\mathrm{O}$ function is detected. In the presence of ester compounds, a strong $\mathrm{C}-\mathrm{O}$ absorption band is detected around 1250-1150 $\mathrm{cm}^{-1}$. The bands around $1200 \mathrm{~cm}^{-1}$ may indicate that the deposit contains ester compounds. On the spectrum, a strong band is visible at $1040 \mathrm{~cm}^{-1}$. This band may be attributed to the C-O bond in a carboxylic acid or an ester, but in this case its intensity is low compared to the two other vibrations observed at 1735 and $1250-1150 \mathrm{~cm}^{-1}$. We can therefore assume that another chemical group is at the origin of this band. This band could be due to oxygenated sulfur compounds such as sulfoxides RS (= O)-R '(strong absorption between 1030 and $1070 \mathrm{~cm}^{-1}$ ) or sulfonate ion (1055 and $1175 \mathrm{~cm}^{-1}$ ). Some bands characteristic of other oxygenated sulfur compounds are also visible. The bands at 1130 and $1320 \mathrm{~cm}^{-1}$ may be due to sulfones RS $(=\mathrm{O})_{2}-\mathrm{R}^{\prime}$. Similarly, the bands at 1180 and $1380 \mathrm{~cm}^{-1}$ can be attributed to compounds of type RS $(=\mathrm{O})_{2}$-OR'. Finally, the two intense bands at 1630 and $1280 \mathrm{~cm}^{-1}$ correspond to the vibration of the $\mathrm{NO}_{2}$ group in an organic nitrate RO-NO $\mathrm{N}_{2}$. 


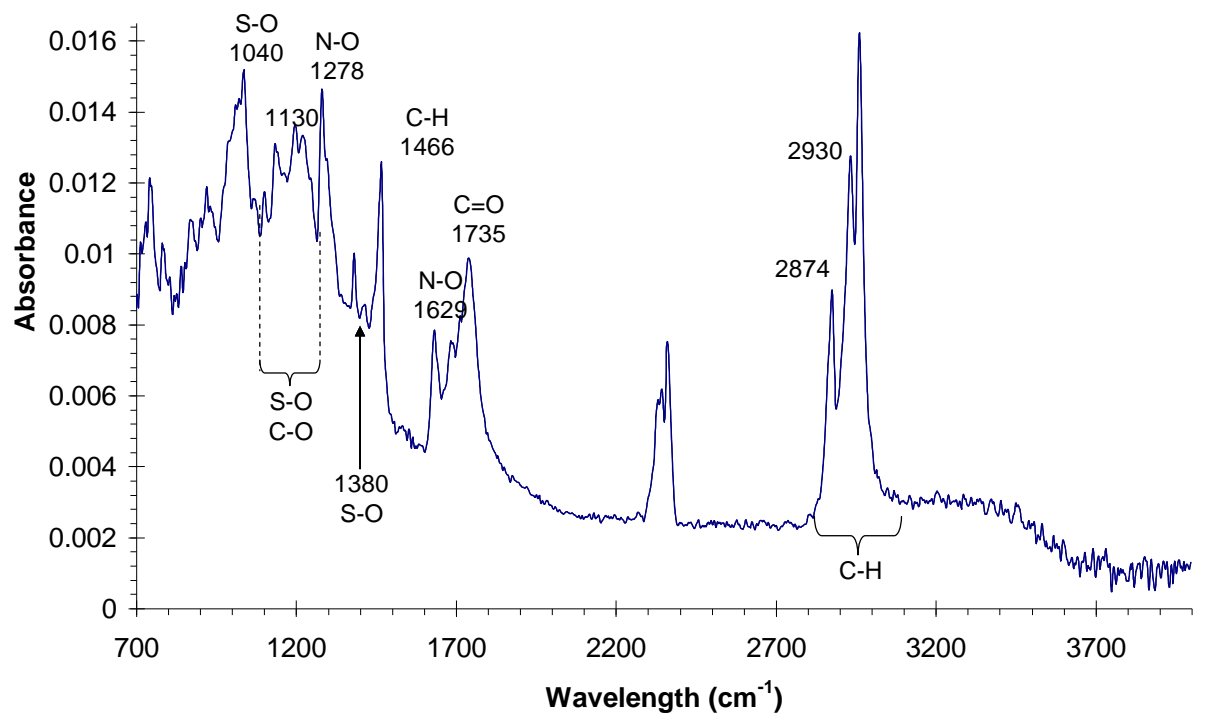

Figure 4. FTIR spectrum

\subsubsection{XPS analysis}

A survey scan was first carried out to obtain the elemental composition of the surface of the polyethylene film covered by the oxidation products. The composition was as follows: carbon $83.3 \%$, oxygen $11.2 \%$, nitrogen $3.6 \%$ and sulfur $3 \%$. These values do not represent the average chemical composition of the oxidation products because the Polyethylene film was only partially covered. However, these results confirm the presence of nitrogen and sulfur in the oxidation products. In a second step, high resolution XPS measurements were carried out to obtain more information on the chemical bonding of the sulphur element in the oxidation products. The deconvolution of the XPS spectrum of sulphur $S_{2 p}$ presented in figure 5 gives two chemical states of sulphur with two peaks at $169,84 \mathrm{eV}$ and 168,54 eV. The full width at half maximum (FWHM) was fixed at $1.95 \mathrm{eV}$ [7]. These binding energies correspond to a high degree of oxidation of sulphur. The functions proposed for a binding energy greater than $168 \mathrm{eV}$ are in increasing order of binding energy: $\mathrm{R}^{-\mathrm{SO}_{3}}{ }^{-}, \mathrm{R}^{-} \mathrm{SO}_{2}-\mathrm{SR}^{\prime}, \mathrm{R}-$ $\mathrm{SO}_{2}-\mathrm{OR}, \mathrm{SO}_{4}{ }^{2-},-\mathrm{SO}_{3}-\mathrm{ROO}$ and $\mathrm{R}-\mathrm{SO}_{2}-\mathrm{OH}[8]$.

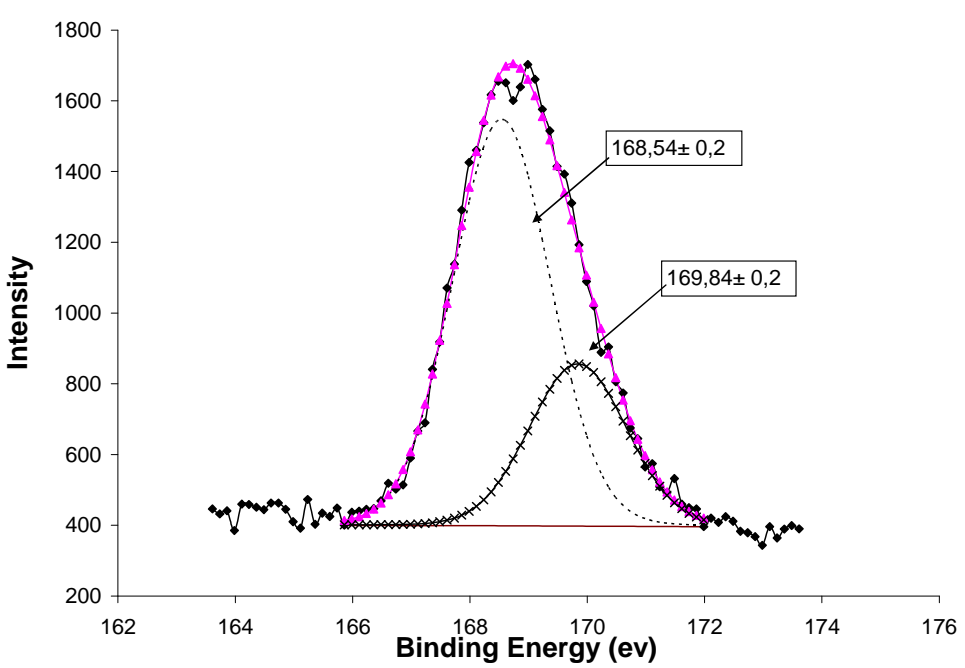

Figure 5. High resolution spectrum of S2p3/2 


\section{Discussion}

The experimental results indicate that the long-life species play a major role in the oxidation of the butyl-mercaptan. In fact, the results obtained in the discharge and post-discharge modes are roughly the same in terms of butyl-mercaptan removal, total VOCs removal, $\mathrm{SO}_{2}$ formation, and nature of oxidation products. It was supposed that $\mathrm{OH}^{\circ}$ and $\mathrm{O}^{\circ}$ radicals could not initiate the reaction with $\mathrm{C}_{4} \mathrm{H}_{9} \mathrm{SH}$ because (i) dry air was used so there was no formation of $\mathrm{OH}^{\circ}$ in the discharge zone and (ii) considering that the life of atomic oxygen in air at atmospheric pressure is about $100 \mu \mathrm{s}$ [20], its concentration was too small in the post-discharge zone to initiate the reaction with butyl-mercaptan.

The long-life species produced by an atmospheric plasma discharge in air have been characterized by Eliasson and Kogelschatz [9]. A single microdischarge in air with a short current pulse of 10 ns duration deposits energy in various excited levels of $\mathrm{N}_{2}$ and $\mathrm{O}_{2}$, some of which lead to dissociation and finally to the formation of ozone and different nitrogen oxides. After about $50 \mathrm{~ns}$, most charge carriers have disappeared and after $10 \mathrm{~ms}$, only long-life species such as $\mathrm{O}_{3}, \mathrm{~N}_{2} \mathrm{O}$, NO, $\mathrm{NO}_{2}, \mathrm{NO}_{3}$ and $\mathrm{N}_{2} \mathrm{O}_{5}$ remain. At low energy density, the concentrations of $\mathrm{NO}_{2}, \mathrm{NO}_{3}$ and $\mathrm{N}_{2} \mathrm{O}_{5}$ are low compared to the concentration of $\mathrm{O}_{3}$. On the opposite, at high energy density, the concentration of $\mathrm{O}_{3}$ become negligible compared to the concentrations of nitrogen species.

The concentrations of $\mathrm{O}_{3}$ and NOx were determined at the reactor outlet in the absence of pollutant injection for the different experimental conditions. The results are summarized in table 3.

Table 3. $\mathrm{O}_{3}$ and NOx concentrations as function of energy density (ppm)

\begin{tabular}{|l|c|c|c|c|c|}
\hline & $100 \mathrm{~J} / \mathrm{L}$ & $200 \mathrm{~J} / \mathrm{L}$ & $450 \mathrm{~J} / \mathrm{L}$ & $600 \mathrm{~J} / \mathrm{L}$ & $1300 \mathrm{~J} / \mathrm{L}$ \\
\hline $\mathrm{O}_{3}(\mathrm{ppm})$ & 200 & 350 & 900 & 300 & nd \\
\hline NOx $(\mathrm{ppm})$ & nd & nd & nd & 100 & 160 \\
\hline
\end{tabular}

These measurements agree qualitatively with those reported by Eliasson and Kogelschatz [9] and Soloshenko et al. [19]. At low energy density, it was not possible to detect nitrogen oxides even if small concentrations of $\mathrm{N}_{2} \mathrm{O}_{5}$ (around two orders of magnitude lower than the ozone concentration) should be present. This may be an artefact of the measurement method caused by interferences with ozone.

Information about reactivity of the long-life species with mercaptans can be found in the literature dealing with atmospheric chemistry [10]. Among the long-life species produced by the atmospheric air discharge, only the nitrate radical $\mathrm{NO}_{3}$ can react with mercaptans. The kinetic constants of the secondorder reactions between $\mathrm{NO}_{3}$ and ethyl-mercaptan $\mathrm{C}_{2} \mathrm{H}_{5}-\mathrm{SH}$ and methyl-mercaptan $\mathrm{CH}_{3}-\mathrm{SH}$ are respectively $1.2 \times 10^{-12}$ [10] and $9.2 \times 10^{-13}[11] \mathrm{cm}^{3}$.molecule ${ }^{-1} \cdot \mathrm{s}^{-1}$ at $298 \mathrm{~K}$ and the reaction mechanism involves hydrogen abstraction from the $-\mathrm{SH}$ bond by the nitrate radical with formation of a radical R$\mathrm{S}^{\circ}$ and nitric acid $\mathrm{HNO}_{3}[12]$ :

$$
\mathrm{R}-\mathrm{SH}+\mathrm{NO}_{3} \rightarrow \mathrm{R}-\mathrm{S}^{\circ}+\mathrm{HNO}_{3}
$$

The radical R-S ${ }^{\circ}$ can then undergo multiple reactions due to reactions with molecular oxygen and/or nitrogen oxides. Basing on the mechanism proposed by Jensen et al.[12], the scheme presented in figure 6 can be suggested for the destruction of mercaptans: 


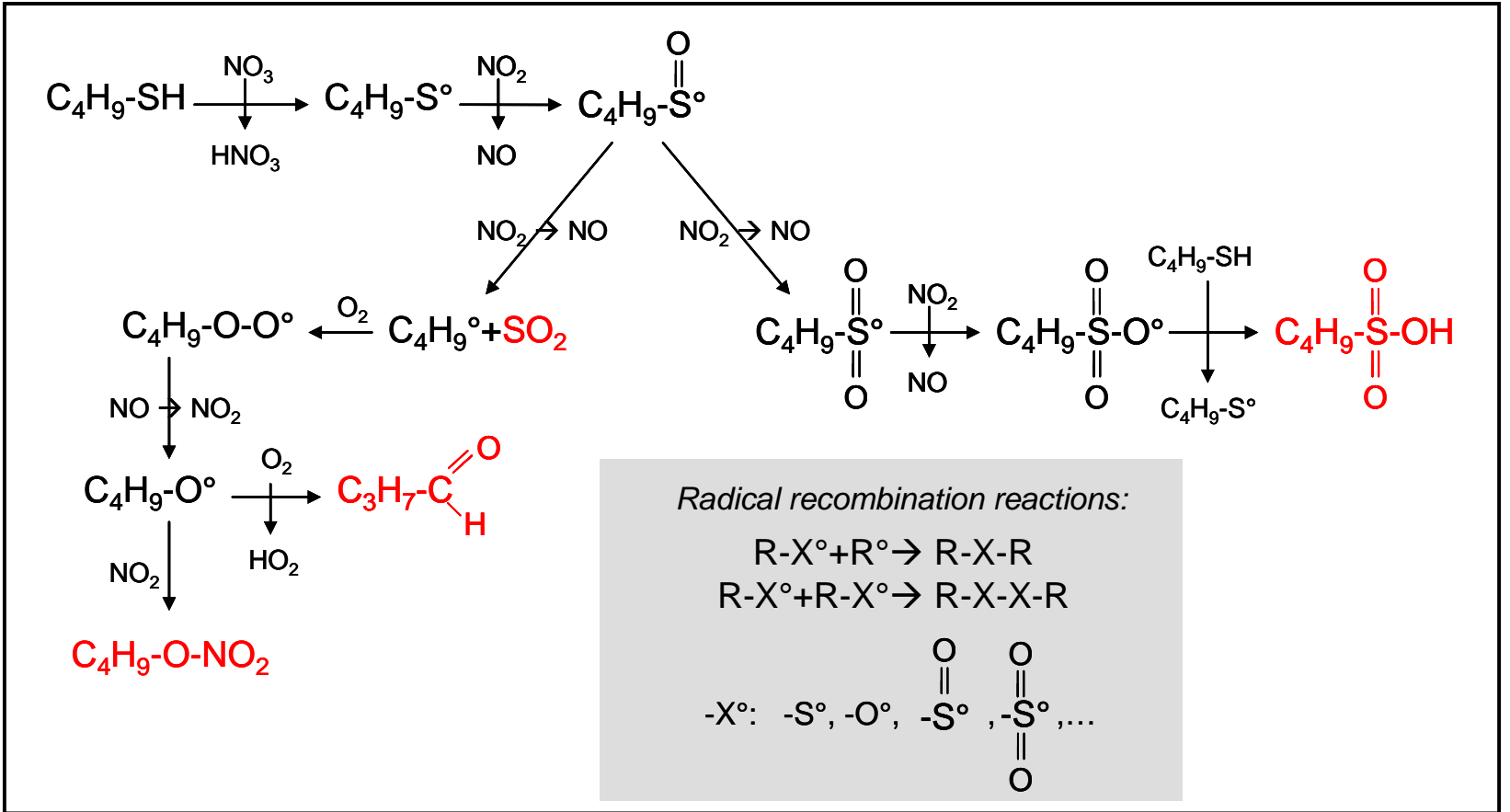

Figure 6. Possible mechanisms for the oxidation of $\mathrm{C}_{4} \mathrm{H}_{9} \mathrm{SH}$ initiated by $\mathrm{NO}_{3}$

According to this reaction scheme, the final reaction products are butanesulfonic acid R-S $(=\mathrm{O})_{2}-\mathrm{OH}$, aldehydes, butyl nitrate R-O- $\mathrm{NO}_{2}$ and $\mathrm{SO}_{2}$. In the conditions of the present study, the concentration of butyl-mercaptan is high and recombination reactions between radicals $\left(\mathrm{RS}^{\circ}, \mathrm{RSO}^{\circ}, \mathrm{RSO}_{2}{ }^{\circ} \ldots\right)$ are also likely to occur with production of high molecular weight compounds.

This mechanism is coherent with the FTIR and XPS analyses presented in 3.2. FTIR analyses indicated the presence of organic compounds with $\mathrm{S}-\mathrm{O}$ or $\mathrm{S}=\mathrm{O}$ functions, aldehyde and/or ester functions as well as -O- $\mathrm{NO}_{2}$ groups and XPS analyses highlighted the high content of sulphur and nitrogen in the reaction products as well as the high oxidation state of sulphur.

It can be noted that sulfonic acids and high molecular weight compounds are likely to condense easily either in a homogeneous way or in a heterogeneous way. This explains the condensation as microdroplets on the reactor wall [13].

The question is: "is the concentration of $\mathrm{NO}_{3}$ sufficiently high in the post-discharge region to account for the measured decomposition of butyl-mercaptan?" In the post-discharge region, there is a dynamic equilibrium between $\mathrm{N}_{2} \mathrm{O}_{5}, \mathrm{NO}_{2}$ and $\mathrm{NO}_{3}$ :

$$
\mathrm{N}_{2} \mathrm{O}_{5} \leftrightarrow \mathrm{NO}_{3}+\mathrm{NO}_{2} \quad \mathrm{Keq}=1.3 \times 10^{12} \mathrm{~cm}^{3} \text {. } \text { molecule }^{-1}
$$

In air at atmospheric pressure, the kinetic constants of the direct and reverse reactions are high:

$$
\begin{array}{ll}
\mathrm{NO}_{3}+\mathrm{NO}_{2} \rightarrow \mathrm{N}_{2} \mathrm{O}_{5} & \mathrm{k}=10^{-12} \mathrm{~cm}^{3} . \text { molecule }{ }^{-1} \cdot \mathrm{s}^{-1} \\
\mathrm{~N}_{2} \mathrm{O}_{5} \rightarrow \mathrm{NO}_{3}+\mathrm{NO}_{2} & \mathrm{k}=2.4 \mathrm{~s}^{-1}
\end{array}
$$

As a consequence, if a fast reaction takes place between butyl-mercaptan and $\mathrm{NO}_{3}$, more $\mathrm{NO}_{3}$ will be produced by the decomposition of $\mathrm{N}_{2} \mathrm{O}_{5}$. However, for low energy densities, the concentrations of $\mathrm{NO}_{2}$ and $\mathrm{N}_{2} \mathrm{O}_{5}$ do not exceed a few ppm. Therefore, it is not possible to explain the decomposition of butylmercaptan experimentally observed by the only reaction between butyl-mercaptan and the radical 
nitrate produced from the decomposition $\mathrm{N}_{2} \mathrm{O}_{5}$. To provide an explanation, the reactions initiated by the radical $\mathrm{C}_{4} \mathrm{H}_{9} \mathrm{~S}^{\circ}$ have to be considered. The radical $\mathrm{C}_{4} \mathrm{H}_{9} \mathrm{~S}^{\circ}$ is initially formed by the reaction between $\mathrm{C}_{4} \mathrm{H}_{9} \mathrm{SH}$ and $\mathrm{NO}_{3}$ :

$$
\mathrm{C}_{4} \mathrm{H}_{9} \mathrm{SH}+\mathrm{NO}_{3} \rightarrow \mathrm{C}_{4} \mathrm{H}_{9} \mathrm{~S}^{\circ}+\mathrm{HNO}_{3}
$$

Once the radical $\mathrm{C}_{4} \mathrm{H}_{9} \mathrm{~S}^{\circ}$ is produced, the following reactions occur $\left(\mathrm{R}=\mathrm{C}_{4} \mathrm{H}_{9}\right)$ :

$$
\begin{array}{ll}
\mathrm{RS}^{\circ}+\mathrm{NO}_{2} \rightarrow \mathrm{RSO}^{\circ}+\mathrm{NO} & \mathrm{R} 2 \\
\mathrm{RSO}^{\circ}+\mathrm{NO}_{2} \rightarrow \mathrm{RSO}_{2}^{\circ}+\mathrm{NO} & \mathrm{R} 3 \\
\mathrm{RS}^{\circ}+\mathrm{O}_{2} \rightarrow \mathrm{RSO}_{2}{ }^{\circ} & \mathrm{R} 4 \\
\mathrm{RSO}_{2}{ }^{\circ}+\mathrm{NO}_{2} \rightarrow \mathrm{RSO}_{3}{ }^{\circ}+\mathrm{NO} & \mathrm{R} 5 \\
\mathrm{RSO}_{3}{ }^{\circ}+\mathrm{RSH} \rightarrow \mathrm{RSO}_{3} \mathrm{H}+\mathrm{RS}^{\circ} & \mathrm{R} 6 \\
\mathrm{NO}+\mathrm{O}_{3} \rightarrow \mathrm{NO}_{2}+\mathrm{O}_{2} & \mathrm{R} 7
\end{array}
$$

In reaction R6, the radical $\mathrm{RSO}_{3}{ }^{\circ}$ reacts with the butyl-mercaptan $\mathrm{RSH}$ by $\mathrm{H}$ abstraction of the $-\mathrm{SH}$ function, producing $\mathrm{RSO}_{3} \mathrm{H}$ as the final product and a new $\mathrm{RS}^{\circ}$ radical. Then, as long as there is $\mathrm{O}_{3}$ in the medium, $\mathrm{NO}_{2}$ can be formed by reaction $\mathrm{R} 7$ between $\mathrm{O}_{3}$ and the $\mathrm{NO}$ generated by reactions $\mathrm{R} 2, \mathrm{R} 3$ and R5 and the chain reaction can go on, causing many of the butyl-mercaptan molecules to be oxidized.

Finally, this simple kinetic model shows that a chain reaction causing the oxidation of RSH could be theoretically initiated by small concentrations of $\mathrm{N}_{2} \mathrm{O}_{5}$. To know if the proposed reaction scheme could explain semi-quantitatively the experimental results obtained at low energy density, chemical kinetic calculations were performed using the simplified kinetic scheme presented in table 4 . As the kinetic constant for reaction R6 was not available, its value was fixed arbitrarily at $10^{-15} \mathrm{~cm}^{3}$.molecule ${ }^{-1} \cdot \mathrm{s}^{-1}$.

Table 4: Reactions implemented in the simplified kinetic scheme

$2^{\text {nd }}$ order reactions

\begin{tabular}{|l|l|l|}
\hline & $\mathrm{k}(298 \mathrm{~K})\left(\mathrm{cm}^{3}\right.$. molecule $\left.{ }^{-1} \cdot \mathrm{s}^{-1}\right)$ & reference \\
\hline $\mathrm{NO}+\mathrm{O}_{3} \rightarrow \mathrm{NO}_{2}+\mathrm{O}_{2}$ & $1.87 \times 10^{-14}$ & {$[10]$} \\
\hline $\mathrm{NO}_{2}+\mathrm{O}_{3} \rightarrow \mathrm{NO}_{3}+\mathrm{O}_{2}$ & $4.46 \times 10^{-17}$ & {$[10]$} \\
\hline $\mathrm{NO}_{3}+\mathrm{NO}_{2} \rightarrow \mathrm{N}_{2} \mathrm{O}_{5}$ & $1 \times 10^{-12}$ & {$[10]$} \\
\hline $\mathrm{RSH}+\mathrm{NO}_{3} \rightarrow \mathrm{HNO}_{3}+\mathrm{RS}^{\circ}$ & $9.2 \times 10^{-13}$ & {$[15] \mathrm{R}=\mathrm{C}_{2} \mathrm{H}_{5}$} \\
\hline $\mathrm{RS}^{\circ}+\mathrm{NO}_{2} \rightarrow \mathrm{RSO}^{\circ}+\mathrm{NO}$ & $6 \times 10^{-11}$ & {$[10] \mathrm{R}=\mathrm{CH}_{3}$} \\
\hline $\mathrm{RS}^{\circ}+\mathrm{O}_{2} \rightarrow \mathrm{RSO}_{2}{ }^{\circ}$ & $2 \times 10^{-14}$ & {$[18] \mathrm{R}=\mathrm{CH}_{3}$} \\
\hline $\mathrm{RSO}^{\circ}+\mathrm{NO}_{2} \rightarrow \mathrm{RSO}_{2}{ }^{\circ}+\mathrm{NO}$ & $1.2 \times 10^{-11}$ & {$[16] \mathrm{R}=\mathrm{CH}_{3}$} \\
\hline $\mathrm{RSO}_{2}{ }^{\circ}+\mathrm{NO}_{2} \rightarrow \mathrm{RSO}_{3}{ }^{\circ}+\mathrm{NO}$ & $4 \times 10^{-12}$ & {$[17] \mathrm{R}=\mathrm{CH}_{3}$} \\
\hline $\mathrm{RSO}_{3}{ }^{\circ}+\mathrm{RSH}^{2} \mathrm{RSO}_{3} \mathrm{H}+\mathrm{RS}^{\circ}$ & \multicolumn{2}{l}{ Not rate data available } \\
\hline
\end{tabular}

$1^{\text {st }}$ order reaction

\begin{tabular}{|l|l|l|}
\hline & $\mathrm{k}(298 \mathrm{~K})\left(\mathrm{s}^{-1}\right)$ & reference \\
\hline $\mathrm{N}_{2} \mathrm{O}_{5} \rightarrow \mathrm{NO}_{3}+\mathrm{NO}_{2}$ & 2.4 & {$[10]$} \\
\hline
\end{tabular}

At $200 \mathrm{~J} / \mathrm{L}$, the concentration of ozone measured experimentally is $350 \mathrm{ppm}$. For concentrations of $\mathrm{NO}_{2}$ and $\mathrm{N}_{2} \mathrm{O}_{5}$, they were supposed to be 3 ppm (around two orders of magnitude lower than the ozone concentration as suggested by Kogelshatz et al. [9]). As the concentration of $\mathrm{NO}_{3}$ at the discharge 
outlet was negligible, its value was supposed to be zero. The results were as follows: the calculated butyl-mercaptan removal was around 30\% what makes sense if compared with the experimental one measured at $200 \mathrm{~J} / \mathrm{L}(60 \%)$. This calculation confirms that the chain reaction causing the destruction of $\mathrm{C}_{4} \mathrm{H}_{9} \mathrm{SH}$ can be initiated with low concentrations of nitrogen oxides. However, the results have to be considered with caution because this is a very simplified reaction scheme and some reactions may not have been taken into account.

The crucial role of long-life species brings also fundamental information on the phenomena taking place in discharge mode. In air at atmospheric pressure, the electrical discharge is filamentary. In the gaseous gap between the two electrodes, we can distinguish two regions [14]: the filamentary volumes where discharge takes place ("discharge" region) and the region outside these volumes ("postdischarge" region) (figure 7). Each time the discharge takes place, electrons and active species such as ions, radicals and excited species are generated in the filamentary volumes. They recombine rapidly into more stable species and can further diffuse in the post-discharge region. The short life duration of radicals such as atomic oxygen $\mathrm{O}^{\circ}$ makes that in the post-discharge region, only the molecules in the close vicinity of the filaments are likely to react with them. As a consequence, if the ratio (filamentary volume/total volume) is low, the reactions involve mainly the long-life species. In the conditions of the present study, it can be therefore supposed that the (filamentary volume)/(total volume) ratio is low.

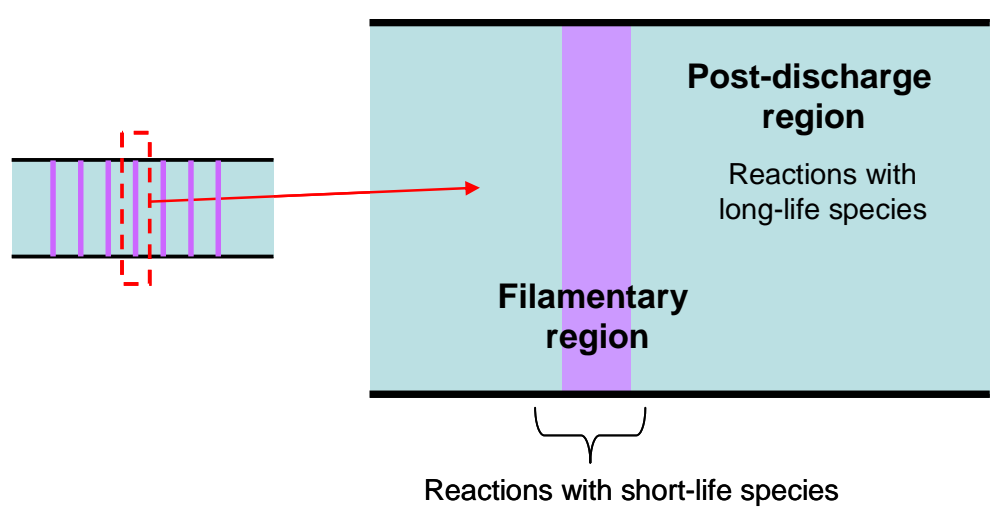

Figure 7. Schematic of the idealized discharge structure

The experimental results have also shown that for a given energy density, the removal of butylmercaptan is slightly higher in the post-discharge mode compared to the discharge mode. To explain this result, we can introduce the yield of the oxidation of butyl-mercaptan defined as follows:

$$
\text { Yield }=\frac{R-S H \text { removed by the discharge }}{O^{\circ} \text { formed by the discharge }}
$$

In the post-discharge mode, the oxygen radicals in the filamentary region are converted partly in NO, $\mathrm{NO}_{2}$ and $\mathrm{NO}_{3}$. The $\mathrm{NO}_{3}$ radicals can react then further in post-discharge region with butyl-mercaptan according to (1). This reaction is selective because the rate constants of $\mathrm{NO}_{3}$ radicals toward oxidation products such as aldehydes, sulfonic acids or $\mathrm{R}-\mathrm{O}-\mathrm{NO}_{2}$ are low compared to the rate constant toward butyl-mercaptan. As a result, a high yield is obtained.

In the discharge mode, some oxygen radicals are converted in $\mathrm{NO}$ and $\mathrm{NO}_{2}$ and $\mathrm{NO}_{3}$ as previously mentioned, whereas other ones react directly not only with butyl-mercaptan but also with its oxidation products. In fact, $\mathrm{O}^{\circ}$ radicals are nonselective toward organic species. As a consequence, in discharge mode, less $\mathrm{NO}_{3}$ is produced and butyl-mercaptan is oxidised with a low yield in the filamentary 
region, which explains why butyl-mercaptan removal is slightly higher in the post-discharge mode compared to the discharge mode.

\section{Conclusion}

In this work, air polluted with butyl-mercaptan was treated with non-thermal DBD plasma in discharge and post-discharge modes. In the two modes, the oxidation reactions took place mainly in post-discharge region. Kinetic calculations supported the hypothesis that nitrate radicals may play a crucial role in the initiation of the chain reaction causing the oxidation of butyl-mercaptan. However, experimental measurements of the concentrations of the key species are still necessary to validate definitely the proposed mechanism. Spontaneous condensation of the oxidation products on the reactor wall was observed, which indicates that the plasma treatment could be used as a pre-treatment to modify the properties of the mercaptans so that they can be trapped further easily using techniques such as condensation, absorption or adsorption. Finally, the results show that if the plasma treatment is carried out with the objective to oxidise partially the mercaptans, the post-discharge mode is the best configuration.

\section{Acknowledgement}

This study is realized with the financial support of Research Fund for International Young Scientists granted by National Natural Science Foundation of China (NSFC) (No. 51050110443).

\section{References}

[1] Li WB, Wang JX, Gong H 2009 Catal. Today 148 1-2 81-87

[2] H, Hao GH, Tseng TK 2003 J. Hazard. Mater. 100 1-3 301-16

[3] Parmar GR, Rao NN 2009 Crit. Rev. Environ. Sci. Technol. 391 41-78

[4] Van Durme J, Dewulf J, Leys C, Van Langenhove H 2008 Appl. Catal. B:Environ. 78 324-33

[5] Chen HL, Lee HM, Chen SH, Chang MB, Yu SJ, Li SN 2009 Environ. Sci. Technol. 43 221627.

[6] Ognier S, Youssef J, Cavadias S, Amouroux J 2008 Int. J. Chem. React. Eng. 6 A27.

[7] Thirumaran S, Ramalingam K, Bocelli G, Righi L 2009 Polyhedron 282 263-268

[8] Siow KS, Britcher L, Kumar S, Griesser HJ 2009 Plasm. Process. Polym. 6 583-92

[9] Eliasson B, Kogelschatz U 1991 IEE Transactions on Plasma Science 19 309-23.

[10] Atkinson R, Baulch DL, Cox RA, Crowley JN, Hampson RF, Hynes RG, M. E. Jenkin ME, Rossi MJ, Troe J 2004 Atm. Chem. Phys. 4 1461-1738

[11] Mac Leod, H, Aschmann SM, Atkinson R, Tuazon EC, Sweetman JA, Winer AM, Pitts JN 1986 J. Geophys. Res 91

[12] Jensen NR, Hjorth J, Lohse C, Skov H, Restelli G 1992 Int. J. Chem. Kin. 2410 839-50

[13] Vandingenen R, Jensen NR, Hjorth J, Raes F 1994 J. Atm. Chem. 183 211-37.

[14] Redolfi M, Aggadi N, Duten X, Touchard S, Pasquiers S, Hassouni K 2009 Plasm. Chem. Plasm. Process. 293 173-195.

[15] Atkinson R. 1991, J. Phys. Chem. Ref. Data 20459 - 507.

[16] DeMore, W.B.; Sander, S.P.; Golden, D.M.; Hampson, R.F.; Kurylo, M.J.; Howard, C.J.; Ravishankara, A.R.; Kolb, C.E.; Molina, M.J. 1997, Chemical kinetics and photochemical data for use in stratospheric modeling. Evaluation number 12, JPL Publication 97-4, 1-266.

[17] Barone, S.B.; Turnipseed, A.A.; Ravishankara, A.R. 1995 Faraday Discuss. 100 39-54.

[18] Zhu, L.; Bozzelli, J.W., 2006, Kinetics of the multichannel reaction of methanethiyl radical (CH3S center dot) with O-3(2), J. Phys. Chem. A v110 6923 - 6937.

[19] Soloshenko IA, Tsiolko VV, Pogulay SS, Terentyeva, A.G, Bazhenov, V.Yu), Shchedrin, AI, Ryabtsev AV, Kuzmichev AI, 2007, PLASMA SOURCES SCIENCE \& TECHNOLOGY V16 56-66. 
[20] Uddi M, Jiang NB, Mintusov E, Adamovich IK, Lempert WR 2009 PROCEEDINGS OF THE COMBUSTION INSTITUTE v. 32 929-936. 